\title{
Influence of clinical practice guidelines on pain management in german intensive care units - A state wide survey
}

\author{
I rmela Gnass, Anna Nimako-Doffour, Gabriele Meyer \\ Department of Nursing Science, Faculty of Health, Witten/Herdecke University, Witten, Germany \\ Correspondence: Irmela Gnass. Address: Department of Nursing Science, Faculty of Health, Witten/Herdecke \\ University, Stockumer Straße 12, 58453 Witten, Germany. Email: Irmela.Gnass@uni-wh.de
}

Received: August 26, 2013

Accepted: September 23, 2013

Online Published: November 25, 2013

DOI : $10.5430 /$ cns.v2n1p37

URL: http://dx.doi.org/10.5430/cns.v2n1p37

\begin{abstract}
Systematic pain assessment in critically ill patients might reduce the number of days with mechanical ventilation as well as the length of hospital stay. Clinical practice guidelines recommend the use of standardized instruments as part of a structured pain assessment strategy for mechanically ventilated patients in intensive care units. Since it is unknown whether clinicians adhere to the recommendations, we conducted a survey focusing the main recommendation of pain and sedation assessment for critically ill patients with mechanical ventilation. A questionnaire consisting of eight items was developed, piloted and sent out to 457 intensive care units in North Rhine-Westphalia, Germany. Nursing directors were asked to forward the questionnaire to the ward nurses or the physicians in charge of the intensive care units. The response rate was $37.4 \%(n=171)$. Nurses from 68 out of 171 intensive care units indicated the use of a pain assessment tool; identified as $n=39$ used self-reporting tools or $n=29$ proxy rating tools; $n=88$ answered to use sedation assessment tools. A total of 801 physiological parameters for pain assessment were stated, most often blood pressure (19.5\%), heart rate (18.6\%), body language (16.7\%), and respiratory rate (16.0\%). Although recommended in the guidelines, our survey indicates that pain assessment tools are rarely used at German intensive care units. It remains unclear how nurses and physicians use pain assessment tools in combination with other parameters for systematic pain assessment. Further research is needed on the barriers of guideline implementation to intensive care units.
\end{abstract}

\section{Key words}

Pain assessment, Intensive care unit, Critical illness, Clinical practice guideline, Survey

\section{I ntroduction}

Caring for critically ill patients in intensive care units (ICUs) is challenging for health care professionals, particular when patients are unconscious ${ }^{[1-3]}$. Throughout the different stages of consciousness, the medication received for pain and anxiety and also the ventilation tube are interfering with effective communication in most cases ${ }^{[3-5]}$. Critically ill patients struggle in many aspects to verbally express pain, which can be a result of the critical illness itself or can be caused by the diagnostic or therapeutic treatment ${ }^{[4,6-8]}$. Conservative estimates suggest that around half of all sedated and mechanically ventilated patients in ICUs suffer from pain despite systematic pain and sedation therapy ${ }^{[9]}$. The reasons for inadequate pain treatment are multifaceted. Insufficient pain assessment by health professionals might be the most important cause. 
Nurses play a decisive role in the identification of pain due to their close contact to the patients ${ }^{[7,10]}$. A number of studies have shown a reduction of the length of hospital stay and duration of mechanical ventilation when systematic pain assessment was effectively conducted ${ }^{[7,11,12]}$.

Recently, national and international clinical practice guidelines have been developed whose implementation might ensure evidence-based care for mechanically ventilated ICU patients with sedation and analgesia therapy ${ }^{[13-15]}$. German guidelines recommend the use of reliable and valid instruments for the assessment of pain ${ }^{[16]}$. In addition, health care professionals should observe critically ill patients with respect to physiological and subjective parameters, like heart rate, movement and facial expression. These data are necessary for the identification of pain and the achievement of the therapy goal, documented in a patient-orientated treatment protocol ${ }^{[16,17]}$. Little is known whether these guideline recommendations have an influence on clinical practice in ICUs ${ }^{[15]}$.

Therefore, the purpose of the study was to investigate whether pain and sedation assessment instruments for sedated and mechanically ventilated patients, as recommended in national guidelines, have been implemented in ICU clinical practice.

\section{Method}

\subsection{Study design}

This multicenter survey was conducted among nurses and physicians in charge of ICUs in North Rhine-Westphalia, the largest federal state in Germany. The study was conducted between August and December 2009.

\subsection{Participants}

A list of ICUs at hospitals in North Rhine-Westphalia was generated from the website of the German Hospital Register ${ }^{[18]}$. Hospitals were contacted by phone in case of doubt whether an ICU was located at the center. Neonate and pediatric ICUs were excluded.

A sample size calculation was not performed since the study aimed to describe the statewide adherence of ICUs to guideline recommendations on pain management and therefore all hospitals in North Rhine-Westphalia were invited to participate.

All 327 eligible hospitals with an ICU were contacted and invited via postal mail to participate. Full confidentiality was assured and the questionnaires provided were pseudonymized. Participants were nurses or physicians with expertise in the field of critical care nursing, regardless of a specific qualification. The recruitment letters were addressed to the nursing directors who were asked to forward the enclosed questionnaire to the ICU ward nurses or the physician in charge of the ICU.

\subsection{I ncentives}

A stamped and self-addressed envelope was added to the invitation letter. In order of response the first three responding ICUs were invited to a local conference on acute pain management, which was held at the end of the data collection period.

\subsection{Questionnaire}

The self-administered questionnaire was developed referring to the evidence-based guideline on pain management in intensive care medicine initiated by the ${ }^{[16]}$. The first author has long lasting experience in the clinical field and was involved in the implementation and evaluation of pain management in different hospitals in Germany. The questionnaire was piloted for comprehensibility and feasibility among ten nurses employing face-to-face interviews in one hospital 
outside North Rhine-Westphalia. Minor modifications in two items were necessary. The final instrument covered eight items on pain and sedation, including the recommended instruments and the observable parameters (see Table 1).

Table 1. Questionnaire

Pain measurement for critically ill adult patients on intensive care units

1. Which parameters do you consider for pain identification?

(Multiple answers are possible)

Body language Facial expression

Vocalization Blood pressure

Heart rate Breathing rate

Others (please indicate):

2. Do you use a pain assessment tool on your unit? Yes No

If the answer is yes, please select!

2a. Which pain assessment tools do you use on your unit?

(Multiple answers are possible)

BPS (Behavioral Pain Scale)

P.A.I.N (Pain Assessment and Intervention Notation algorithm)

CPOT (Critical-Care Pain Observation tool)

NVPS (Nonverbal Adult Pain Assessment Scale)

Other (Please indicate):

3. Who measures pain in sedated and ventilated patients? (i.e. nurses or physicians)

Please describe:

4. Which parameter/s do you consider to detect the state of sedation?

(Multiple answers are possible)

Restlessness/cooperation Respond to verbal contact

Agitation Technical measurements (EEG, AEP)

Reaction to sensory touch Neuromuscular monitoring

Other (please indicate):

5. Do you use a sedation assessment tool?

Yes No

If the answer is yes, please select!

5a. Which sedation assessment tools do you use on your unit?

(More than one answer is possible)

RSS (Ramsey-Sedation-Scale)

VICS (Vancouver Interaction and Calmness Scale)

RASS (Richmond Agitation Sedation Score)

MAAS (Motor Activity Assessment Scale)

SAS (Sedation-Agitation-Scale)

Other (please indicate):

6. Do you use a specific clinical guidance/algorithm for therapy of pain and sedation?

Yes No

If the answer is yes:

6a. Does it include a recommendation for a specific pain assessment tool considering the sedation status?

Yes No

If the answer is yes, please describe the process taking the different sedation levels into account:

7. What is your occupational role?

Nurse (team member)

Nurse specialist

Staff nurse

Nurse director

Other (please indicate):

8. What is the specialty of the intensive care unit you are working in?

Intensive care unit for internal medicine

Surgical intensive care unit

Interdisciplinary intensive care unit

Cardio-surgical intensive care unit

Other (please indicate):

Published by Sciedu Press 


\subsection{Definitions}

Pain measurement was defined for pain intensity by using self-reporting pain assessment tools like the Numeric Rating Scale (NRS) ${ }^{[19]}$ and for tools using observational measures like the Behavioral Pain Scale (BPS) ${ }^{[20]}$.

Sedation level measurement - as an important aspect for the decision on the appropriate pain assessment tool - was defined through sedation assessment tools recommended in the guideline ${ }^{[19]}$.

Further parameters defined by the recommendation of the German guideline like subjective parameters (e.g. movement) and physiological parameters (e.g. blood pressure) were included ${ }^{[19]}$.

Beyond the data on occupational function the questionnaire comprised the recommended pain assessment scales, further parameters and an option to contribute other scales or parameters not covered by the questionnaire.

\subsection{Data analysis}

The data were entered in IBM SPSS statistics 18.0 by one author (AND) and a $10 \%$ random sample was checked by a second author (IG). The results for occupational affiliation and the responses to the questionnaires were recorded as frequencies.

\section{Results}

The questionnaires were sent out to 457 ICUs located in 325 hospitals from which 171 ICUs responded (response rate $37.4 \%)$.

Table 2. Clinical expertise of responding ICUs

\begin{tabular}{llll}
\hline Intensive care units $(\mathbf{n}=\mathbf{1 7 1})$ & $\mathbf{n}$ & $\mathbf{\%}$ \\
\hline Medical ICUs & 14 & 8.2 \\
& Trauma ICUs & 32 & 18.7 \\
& Cardiological & 6 & 3.5 \\
Clinical expertise & Interdisciplinary & 93 & 54.4 \\
& Other & 7 & 4.1 \\
& Multiple answers & 9 & 5.3 \\
& Not stated & 10 & 5.8 \\
& Total & 171 & 100 \\
\hline
\end{tabular}

\subsection{Sample}

As shown in Table 2, ten out of 171 ICUs did not state their clinical expertise. Approximately half of the ICUs are interdisciplinary. The questionnaire was predominantly filled in by nurses (94.8\%), of them the majority (66\%) were staff nurses, $17.4 \%$ team member nurses, $9.6 \%$ specialized nurses, and $1.8 \%$ nurse directors.

\subsection{Pain measurement tools}

Of the 171 responding ICUs 68 (39.8\%) reported the use of pain measurement tools; identified as $n=39(22.8 \%)$ self-reporting scales or n=29 (17\%) observational measurement tools (see Figure 1).

Figure 1 displays the pain assessment tools in use for mechanically ventilated/non communicating patients in the ICUs. 


\title{
Pain assessment tools $(n=68)$
}

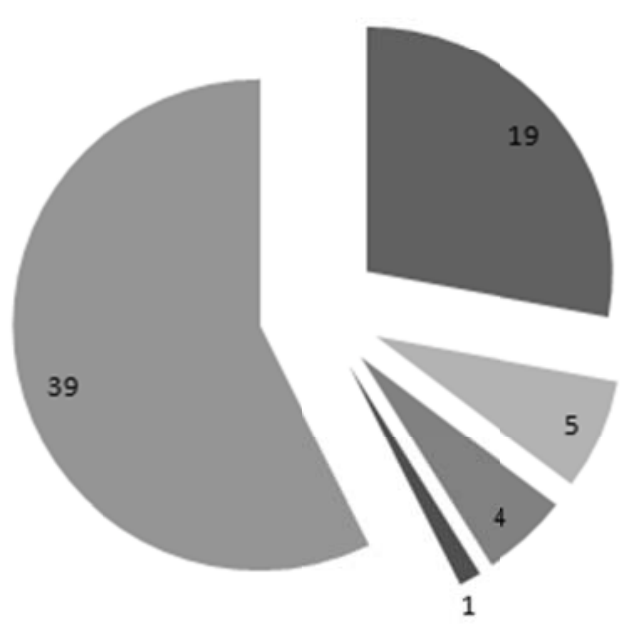

\author{
- Behavioral Pain Assessment \\ (BPS) \\ Non Verbal Pain Scale \\ - Pain Asseessment and \\ Intervention Notation Tool \\ - Crtitical Care Pain \\ Oberservational Tool (CPOT) \\ n Self-report Scales (e.g. NRS)
}

Figure 1. Used pain assessment tools

\subsection{Additional parameters}

A total of 801 additional parameters for pain identification were mentioned. Nominations of physiological or subjective parameters were equally represented: blood pressure (19.5\%), heart frequency (18.6\%) and respiratory frequency (16.0\%) as often as facial expression (19.3\%) and body language (16.7\%). Vocalization (7.0\%) for pain assessment was less often mentioned.

\subsection{Sedation level scales}

Scales for assessment of sedation level were mentioned to be in use at 88 out of 171 ICUs (51.5\%); n=82 (48\%) did not to use a scale. The Ramsey Sedation Scale (RSS) was the most frequently used instrument ( $n=62,36.3 \%)$ followed by the Richmond Agitation Sedation Scale ( $\mathrm{n}=29,16.9 \%)$. Both, the Sedation Agitation Scale and the Glasgow Coma Scale were rarely used, i.e. each in $n=3$ ICUs (3.4\%). The results show that few ICUs use more than one sedation level scale.

\subsection{Additional parameters for sedation level}

A total of 660 additional parameters for sedation levels were mentioned. Restlessness (24.4\%), response to verbal contact (25\%) and response to sensory touch (24.2\%) were mentioned equally often. Whereas agitation (0.9\%), diagnostic measures like electroencephalogram (1.5\%) and neuromuscular blocking and also agent monitoring (0.6\%) were mentioned rather rarely. Further parameters like heart rate, respiratory rate, level of consciousness, respiratory minute volume, pain and coughing were also mentioned.

\subsection{Clinical guidelines (Algorithm)}

Seventy ICUs (40.9\%) stated to have specific clinical guidelines (algorithm) in place, which cover recommendations for a specific pain assessment tool and consider the sedation level. Those ICUs, which have clinical guidelines established, did not mention the decision making process taking different sedation levels into account. Measurement of pain in sedated and ventilated patients was most often described as a task for nurses ( $n=145 ; 84.8 \%)$, in $n=26$ ICUs (15.2\%) as task for physicians, and in 10 ICUs for both professions. 


\section{Discussion}

The survey with 171 ICUs in North Rhine-Westphalia, Germany, revealed that guideline recommendations on the application of observational pain assessment tools for sedated and mechanically ventilated patient are predominately not implemented. Pain assessment tools are slightly more often present for awake patients able to express their pain verbally (e.g. NRS) than for sedated patients who cannot express their pain verbally (e.g. CPOT).

Approximately half of the ICUs stated the use of scales for measuring the sedation level. The Ramsey Sedation Scale (RSS) - an instrument recommended in the national guideline released in 2005 - was most often stated to be in use. For this reason, the RSS was found more widely used than indicated in an earlier survey by Martin and colleagues in $2007^{[17,19]}$.

Nearly all nurses and physicians mentioned the parallel use of physiological or subjective parameters and validated and reliable pain assessment tools.

Based on the survey one might not conclude how health care professionals use physiological parameter. Therefore, it has to be questioned why they mentioned them for pain or assessment. Physiological parameters for pain identification as a primary indicator can be misleading due to physiological condition, homeostatic changes or medications and are currently not be recommended to be used alone for pain assessment ${ }^{[21,22]}$. Furthermore, the use is critically due to the fact that assessment with pain parameters are influenced by misconception, personal perceptions and experience of pain by the assessor. Therefore, the diverse pain assessments with physiological parameters would have an influence on pain identification, pain therapy, side effects as well as patient wellbeing ${ }^{[23]}$.

Recent publications suggest various ways to integrate pain assessment tools for unconscious or sedated/ventilated patients into sedation-controlled algorithms ${ }^{[11,24-27]}$.

Kastrup and colleagues (2009) demonstrated that structured documentation of pain/pain intensity and sedation/sedation levels are independently correlated with better outcomes (reduce of mortality) in the ICU, and that the assessment of pain influences the length of time on ventilation and stay in the ICU ${ }^{[28]}$. The existing evidence does not indicate which of the various algorithms reach the most effective outcome for patients in the ICU.

The guideline for pain management, which was the basis for the development of the questionnaire, comprises evidencebased recommendations usable for the development of various algorithms to guide appropriate health care decisions. The results of the study raise the question how decisions about pain therapy are actually performed while pain assessment tools are rarely used and the use of further parameters is unclear. Future studies should explore the barriers and facilitators for use of a systematic pain assessment by nurses and physicians. One research question might be how professionals use pain assessment tools beside physiological or subjective parameters for pain identification and how the results guide decisions about pain treatment.

There is an urgent need for the implementation of evidence-based recommendations on pain assessment as an integral part of pain management. Pasero, Puntillo, Li et al. (2009) discovered some barriers towards pain management, e.g. knowledge deficits and communication difficulties ${ }^{[29]}$. Strategies for continuous quality improvement must focus on the individual ICU to overcome knowledge deficits, e.g. on pain assessment, pain therapy and responsibilities of involved health professions. These barriers are not researched for Germany so far, but it can be assumed that they exist and influence the implementation of the guideline in German ICU likewise ${ }^{[30]}$. One strategy, which is likely to positively influence the quality improvement of pain assessment, is an external audit procedure on the performance of hospital pain therapy ${ }^{\text {[31] }}$. Around 80 hospitals in Germany improved their quality of pain management through an external audit by selfcommitment so far ${ }^{[32]}$. 


\section{Limitation of the study}

The study has limitations that are worthy of consideration. Despite efforts to ensure a high response rate through proven response increasing techniques ${ }^{[33]}$, only $37.4 \%$ of ICUs returned the questionnaire. Sending the questionnaire to the nursing directors, asking them to forward it to eligible persons on the ICUs without sending a reminder for participation during data collection might have had a strong influence on the response rate. Although, North Rhine-Westphalia is the largest federal state in Germany with 17.8 million citizens, it might be argued that the results of one area are not necessarily applicable to the entire country. However, it should be noticed that our results are comparable to the earlier study conducted by Martin et al. (2007) who included ICUs from 269 hospitals throughout Germany. Thus, the generalizability of our study is most likely ${ }^{[15]}$.

\section{Conclusion}

The study highlights known phenomena and the need to develop specific strategies on effective and efficient guideline implementation for pain assessment for sedated and mechanically ventilated patients in ICUs. It also emphasizes the need to identify barriers towards structured interdisciplinary approaches to pain management in the unique intensive care units.

\section{References}

[1] Jeitziner MM. \& Hantikainen V. Möglichkeiten und Grenzen der Schmerzerfassung bei beatmeten Patienten auf Intensivstation. In Meyer G, Friesacher V \& Lange G (Eds.), Handbuch der Intensivpflege: Ecomed. 2008.

[2] Puntillo K. Pain experiences of intensive care units patients. Heart Lung. 1990; 19(5): 526-533. PMid:2211161

[3] Schweickert WD \& Kress JP. Strategies to Optimize Analgesia and Sedation. Critical Care. 2008; 12(3):S5.

[4] Carroll SM. Silent, Slow Lifeworld: The Communication Experience of Nonvocal Ventilated Patients. Qual Health Res. 2007; (17):1165-1177. PMid:17968034 http://dx.doi.org/10.1177/1049732307307334

[5] Pudas-Tähkä SM, Axelin A, Aantaa R, Lund V, \& Salanterä S. Pain assessment tools for unconscious or sedated intensive care patients: a systematic review. Journal of Advanced Nursing. 2008; 65(5):946-956. PMid:19291192 http://dx.doi.org/10.1111/j.1365-2648.2008.04947.x

[6] Maier J, Handel E, \& Spirig R. ZOPA (c) - Wenn der Schmerz keine Sprache mehr hat. PflegenIntensiv. 2011; 3: 28-31.

[7] Payen JF, Bosson JL, Chanques G, Mantz J, \& Labarere J. Pain Assessment is Associated with Decreased Duration of Mechanical Ventilation in the Intensive Care Unit: a post hoc analysis of the DOLOREA Study. Anaesthesiology. 2009; 6: $1308-1316$. PMid:19934877 http://dx.doi.org/10.1097/ALN.0b013e3181c0d4f0

[8] Tausch S, Rocholl A, Berg A, Becker R, Horbach A, Neubert, TR, Fleischer S. Kommunikation mit Intensivpatienten - (k)ein Problem!? Intensiv. 2011; 19(2):86-92. http://dx.doi.org/10.1055/s-0031-1272895

[9] Chanques G, Jaber S, Barbotte E, Violet S, Sebbane M, Perrigault PF, Mann C, Lefrant JY, Eledjam JJ. Impact of systematic evaluation of pain and agitation in an intensive care unit. Critical Care Medicine. 2006; 34(6):1691-1699. PMid:16625136 http://dx.doi.org/10.1097/01.CCM.0000218416.62457.56

[10] Pasero C. Assessment of Sedation During Opioid Administration for Pain Management. Journal of PeriAnesthesia Nursing. 2009; 24(3): 186-190. PMid:19500754 http://dx.doi.org/10.1016/j.jopan.2009.03.005

[11] Kress JP, Pohlmann AS, O'Connor MF \& Hall HB. Daily Interruption of Sedative Infusions in Critically Ill Patients Undergoing Mechanical Ventilation. The New England Journal of Medicine. 2000; 342(20): 1471-1477. PMid:10816184 http://dx.doi.org/10.1056/NEJM200005183422002

[12] Williams TA, Martin S, Leslie G, Thomas L, Leen T, Tamaliunas S, Lee KY, Dobb G. Duration of Mechanical Ventilation in an Adult Intensive Care Unit after Introduction of Sedation and Pain Scales. American Journal of Critical Care. 2008; 17(4): 349-356. PMid:18593834

[13] ANZCA (Australian and New Zealand College of Anaesthetists and Faculty of Pain Medicine). Acute Pain Management: Scientific Evidence. Melbourne: ANZCA; 2010.

[14] DIVS (Deutsche Interdisziplinäre Vereinigung für Schmerztherapie). S3-Leitlinie "Behandlung akuter perioperativer und posttraumatischer Schmerzen - Langfassung". 2007 [cited 2008 June 23] R-Nr:041/001. Available from http://www.awmf.org 
[15] Martin J, Franck M, Sigel S, Weiss M, Spies C. Changes in sedation management in German intensive care units between 2002 and 2006: a national follow-up survey. Critical Care [Internet]. 2007 [cited 2008 June 23]; 11: R124. Available from http://ccforum.com/content/11/6/R124.

[16] DGAI \& DIVI (Deutsche Gesellschaft für Anästhesie und Intensivmedizin \& Deutsche Interdisziplinäre Vereinigung für Intensiv und Notfallmedizin). Analgesie, Sedierng und Delirmanagement in der Intensivmedizin. 2010 [cited 2010 Jan 20]; R-Nr 001-012. Available from: http://www.awmf.org/leitlinien/detail/ll/001-012.html

[17] Martin J, Heymann A, Bäsell K, Baron R, Biniek R, Bürke H, et al. Evidence and consensus-based German guidelines for the management of analgesia, sedation and delirium in intensive care - short version. GMS German Medical Science. 2010 ; 8: Doc02. PMid:20200655

[18] DKTIG (Deutsche Krankenhaus Trust Center und Informationsverarbeitungs GmbH). Deutsches Krankenhaus Verzeichnis. [cited 2009 Sept 20]. Available from: http://www.deutsches-krankenhaus-verzeichnis.de

[19] DGAI (Deutsche Gesellschaft für Anästhesiologie und Intensivmedizin). Analgesie und Sedierung in der Intensivmedizin Kurzversion. Anästhesie Intensivmedizin, 2005;46(Supp.-Nr. 1):1-20.

[20] Payen JF, Bru O, Bosson JL, Lagrasta A, Novel E, Deschaux I, et al. Assessing pain in critically ill sedated patients by using a behavioral pain scale. Critical Care Medicine. 2001; 29(12): 2258-2263. PMid:11801819 http://dx.doi.org/10.1097/00003246-200112000-00004

[21] Herr K, Coyne PJ, McCaffery M, Manworren R \& Merkel S. Pain Assessment in the Patient Unable to Self-Report - Position Statement with Clinical Practice Recommendations. Pain Management Nursing. 2011; 12(4): 230-250. PMid:22117755 http://dx.doi.org/10.1016/j.pmn.2011.10.002

[22] Barr J, Fraser GL, Puntillo K, Ely EW, Gélinas C, Dasta JF, et al. Clinical Practice Guidelines for the Management of Pain, Agitation, and Delirium in Adult Patients in the Intensive Care Unit [Internet]. 2013 [cited 2013 May 25]. Available from: http://www.learnicu.org

[23] Young JL, Horton FM, Davidhizar R. Nursing Attitudes and Beliefs in Pain Assessment and Management. Journal Compilation. 2005:412-421. PMid:15816781

[24] Arias-Rivera S, Sánchez-Sánchez MdM, Santos-Díaz R, Gallardo-Murillo J, Sánchez-Izquierdo R, Frutos-Vivar F, et al. Effect of a nursing-implemented sedation protocol on weaning outcome. Critical Care Medicine. 2008; 36(7): 2054-2060. PMid:18552689 http://dx.doi.org/10.1097/CCM.0b013e31817bfd60

[25] De Jonghe B, Bastuji-Garin S, Fangio P, Lacherade JC, Jabot J, Appéré-De-Vecchi C, et al. Sedation algorithm in critically ill patients without acute brain injury. Critical Care Medicine. 2005; 33(1): 120-127. PMid:15644658 http://dx.doi.org/10.1097/01.CCM.0000150268.04228.68

[26] Elliott R, McKinley S, Aitken L \& Hendrikz J. The effect of an algorithm-based sedation guideline on the duration of mechanical ventilation in an Australian intensive care unit. Intensive Care Medicine. 2006; 32: 1506-1514. PMid:16896847 http://dx.doi.org/10.1007/s00134-006-0309-0

[27] Riker RR \& Fraser GL. Monitoring Sedation, Agitation, Analgesia, Neuromuscular Blockade, and Delirium in Adult ICU Patients. Seminars in Respiratory and Critical Care Medicine, 2001; 22(2): 189-198. PMid:16088673 http://dx.doi.org/10.1055/s-2001-13832

[28] Kastup M, Dossow VV, Seeling M, Ahlborn R, Tamarkin A, Conroy P, Boemke W, Wernecke KD, Spies C. Key Performance Indicators in Intensive Care Medicine. A Retrospective Matched Cohort Study. The Journal of International Medical Research. 2009; 37(5): 1267-1284. http://dx.doi.org/10.1177/147323000903700502

[29] Pasero C, Puntillo K, Li D, Mularski RA, Grap MJ, Erstad BL, Varkey B, Gilbert HC, Medina J, Sessler CN. Structured Approaches to Pain Management in the ICU. Chest. 2009; 35(6): 1665-1672. PMid:19497902 http://dx.doi.org/10.1378/chest.08-2333

[30] Grimshaw J, Thomas R, MacLennan G, Fraser C, Ramsay C, Vale L, et al. Effectiveness and efficiency of guideline dissemination and implementation strategies. Health Technology Assessment. 2004; 8(6). PMid:14960256

[31] Maier C, Nestler N, Richter H, Hardinghaus W, Pogatzki-Zahn E, Zenz M, Osterbrink J. (2010). Qualität der Schmerztherapie in deutschen Krankenhäusern. Deutsches Ärzteblatt. 2010; 107(36): 607-614.

[32] Certkom e V. Gesellschaft für Qualifizierte Schmerztherapie [Association for Quality in Pain therapy] [Internet]. [cited 2012 Oct 28]. Available from: www.certkom.com

[33] Edwards P, Roberts I, Clarke M, DiGuiseppi C, Pratap S, Wentz R, Kwan I. Increasing response rates to postal questionnaires: systematic review. Britisch Medical Journal. 2002; 324: 1183. http://dx.doi.org/10.1136/bmj.324.7347.1183 